\title{
O ENSINO DE QUÍMICA COMO UNIDADE DIALÉTICA ENTRE OS NÍVEIS MACROSCÓPICOS E SUBMICROSCÓPICOS: para além do triângulo de Johnstone
}

\author{
Caio de Souza Silval \\ Hélio da Silva Messeder Neto²
}

\begin{abstract}
RESUMO
No ensino de química há uma adoção quase hegemônica das ideias do professor Alex Johnstone sobre os três níveis representacionais do conhecimento químico, os quais ficaram conhecidos como triângulo de Johnstone: macroscópico, submicroscópico e simbólico. Nesse sentido, muitos trabalhos tomam essa ideia como um embasamento quase natural e focalizam o debate na forma de torná-lo didático, deixando em segundo plano discussões epistemológicas necessárias. No entanto, este trabalho tem como objetivo contribuir com a crítica ao triângulo de Johnstone e promover uma discussão que gere uma nova compreensão da realidade sobre os níveis do conhecimento químico, isto, através da perspectiva do materialismo histórico-dialético e da psicologia histórico-cultural. Esses fundamentos nos levaram a propor que a química se fundamenta na unidade dialética entre dois níveis da realidade, o macroscópico e submicroscópico, mediados pela representação. Além disso, apontamos princípios da prática pedagógica para que a nossa concepção pudesse ganhar materialidade para o campo do ensino de química.
\end{abstract}

Palavras-chave: Triângulo de Johnstone. Níveis da representação química. Teoria histórico-cultural da atividade.

\section{CHEMISTRY TEACHING AS A DIALECTIC UNIT BETWEEN MACROSCOPIC AND SUBMICROSCOPIC LEVELS: beyond the Johnstone's triangle}

\begin{abstract}
There is an almost hegemonic adoption of Professor Alex Johnstone's ideas on the three levels of representation of chemical knowledge in Chemical Education. Each of those levels-macroscopic, submicroscopic, and symbolic levels-forms what we know as the Johnstone's triangle. Tons of research take that conception as a nearly

\footnotetext{
${ }^{1}$ Mestre em Ensino, Filosofia e História das Ciências pelo Programa de Pós-Graduação em Ensino, Filosofia e História das Ciências, UFBA/UEFS; Professor de Química da Secretaria de Educação do Estado da Bahia, Salvador-BA, Brasil. Membro do Grupo de Pesquisa Enconciências. Orcid iD: https://orcid.org/0000-0001-8261-8725. E-mail: caioss404@gmail.com

2 Doutor em Ensino, Filosofia e História das Ciências pelo Programa de Pós-Graduação em Ensino, Filosofia e História das Ciências, UFBA/UEFS. Professor do Instituto de Química na Universidade Federal da Bahia, Salvador-BA, Brasil. Professor Permanente do Programa de Pós-Graduação em Ensino, Filosofia e História das Ciências; Líder do Grupo de Pesquisa Enconciências. Orcid iD: http://orcid.org/0000-0002-6620-2989. E-mail: helioneto@ufba.br
} 
natural foundation, focusing the debate on making the Johnstone's triangle more didactic, but they generally take the most needed epistemological aspects of such theoretical enterprise for granted. This work attempted to contribute with a critique of the Johnstone's triangle so that the discussion herein promoted may offer a new comprehension of the reality of the chemical knowledge through a materialistic, historical, and dialectic perspective, mainly anchored on the Cultural-Historical Activity Theory. Furthermore, we have drawn up principles of the pedagogical practice so that our conception could be as concrete as possible for the Chemical Education field.

Keywords: Johnstone's triangle. Levels of chemical representation. Cultural-Historical Activity Theory.

\section{LA ENSEÑANZA DE LA QUÍMICA COMO UNIDAD DIALÉCTICA ENTRE LOS NIVELES MACROSCÓPICO Y SUBMICROSCÓPICO: más allá del triángulo de Johnstone}

\section{RESUMEN}

En la educación química hay una adopción casi hegemónica de las ideas del profesor Alex Johnstone sobre los tres niveles representacionales del conocimiento químico, que se conocieron como el triángulo de Johnstone: macroscópico, submicroscópico y simbólico. En este sentido, muchos trabajos toman esta idea como una base casi natural y enfocan el debate en cómo hacerla didáctica, dejando en un segundo plano las necesarias discusiones epistemológicas. Sin embargo, este trabajo tiene como objetivo contribuir a la crítica del triángulo de Johnstone y promover una discusión que genere una nueva comprensión de la realidad en los niveles del conocimiento químico a través de la perspectiva del materialismo histórico-dialéctico y la psicología histórico-cultural. Estos fundamentos nos llevaron a proponer que la química se basa en la unidad dialéctica entre dos niveles de realidad, el macroscópico y el submicroscópico, mediado por la representación. Además, señalamos principios de la práctica pedagógica para que nuestra concepción ganara materialidad para el campo de la enseñanza de la química.

Palabras clave: Triángulo de Johnstone. Niveles de representación química. Teoría histórico-cultural de la actividad.

\section{INTRODUÇÃO}

A preocupação com a melhoria do processo de ensino e aprendizagem da Química conduziu, e continua conduzindo, muitos pesquisadores para esse campo de estudo. Foi nesse sentido que o professor Alex $H$. Johnstone formulou um modelo com diferentes níveis de representação do conhecimento químico. Há mais de trinta anos, o supracitado autor escreveu um artigo intitulado Macro and micro-chemistry, com o qual foi pioneiro em propor que a química deve ser compreendida 
em três níveis: macroscópico, submicroscópico e simbólico (JOHNSTONE, 1982).

De acordo com Johnstone (1993), o nível macroscópico está relacionado com o "tangível, comestível, visível" (JOHNSTONE, 1993, p. 703, tradução nossa). Neste mesmo sentido, outros autores tomam esse nível como podendo ser um fenômeno adquirido pelos sentidos ou suas extensões (GILBERT; TREAGUST, 2009; RAUPP; SERRANO; MOREIRA, 2009). Também chamado de fenomenológico, consiste das propriedades empíricas e perceptíveis com relação aos sólidos, líquidos e gases, podendo ser medidas (GILBERT; TREAGUST, 2009). De acordo com Treagust, Chittleborough e Mamiala (2003), o nível macro refere-se aos fenômenos observáveis do dia a dia, como a mudança na coloração e o aparecimento ou $O$ desaparecimento de substâncias, por exemplo.

O nível submicroscópico, para Johnstone (1993), está relacionado com o "molecular, atômico" (JOHNSTONE, 1993, p. 703, tradução nossa). Esse nível é utilizado para explicar qualitativamente o fenômeno, envolvendo partículas, átomos, moléculas, íons etc. (GILBERT; TREAGUST, 2009).

Já o nível simbólico, ou representacional, está relacionado com as fórmulas químicas, os "símbolos, equações, estequiometria e matemática" (JOHNSTONE, 1993, p. 703, tradução nossa).

No contexto brasileiro, os níveis de representação de Johnstone assumiram novas perspectivas e nomenclaturas. Assim, ao referir-se ao nível macro, é possível encontrá-lo nomeado como macroscópico, empírico ou fenomenológico; o submicro também é chamado de submicroscópico, microscópico, teórico ou nível de modelos; já o simbólico também pode ser encontrado como nível de linguagem ou representacional (MORTIMER; MACHADO; ROMANELLI, 2000).

Os níveis do conhecimento químico ficaram conhecidos como triplete do conhecimento químico (TALANQUER, 201 1) ou triângulo de Johnstone. 
Figura 1 - Os três componentes básicos da "nova Química"

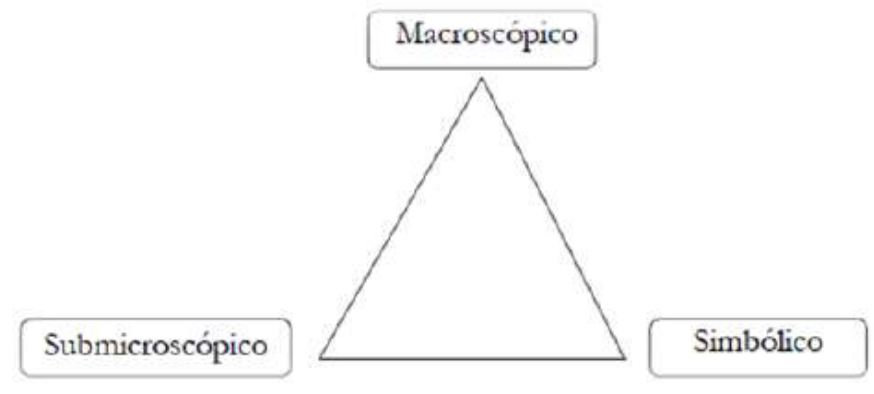

Fonte: Adaptado de Johnstone (1993).

Parece-nos, por vezes, que o modelo de Johnstone se tornou uma forma quase definitiva de encarar a atividade de representação no ensino de química e, nesse sentido, gostaríamos de apresentar algumas considerações.

De acordo com Melo, V. e Silva, J. (2020), a elaboração do triângulo de Johnstone repercutiu positivamente na comunidade internacional de Educação Química, apesar de não ser isenta de críticas. Os mesmos autores (MELO, V.; SILVA, J., 2020) apresentam algumas críticas ao modelo do triângulo e propõem uma definição mais fundamentada sobre a concepção de "níveis", o que, de acordo com eles, sanaria a confusão existente pela forma vaga e simplista que aparece nos trabalhos de Johnstone.

De acordo com Wartha e Rezende (2011), o modelo apresentado por Johnstone, apesar de já ter mais de três décadas da sua primeira publicação, ainda é muito utilizado e propagado pelos pesquisadores em Educação Química. É notória a hegemonia que paira no campo do ensino de química sobre o triângulo de Johnstone, pois ele parece ser o principal e único modelo que discute a questão das representações no ensino dessa ciência, sugerindo não encontrar qualquer divergência sobre o modelo.

Com isso, acreditamos que a boa aceitação do triângulo de Johnstone pode ser justificada pela sua preocupação pioneira em relação à concepção de que o ensino de química precisa ser preferencialmente pautado na promoção do pensamento dos estudantes, para que estes possam ter a capacidade de transitar entre os três níveis do conhecimento de forma equitativa. 
Tal concepção levou pesquisas da área de ensino de química a centrarem as discussões, quase hegemonicamente, nas formas e estratégias de colocarem a ideia dos três níveis em prática. O próprio Johnstone (2004) recomendou que os professores de química criassem situações reais que pudessem mostrar o universo macroscópico ao aluno, acompanhado da simbologia química pertinente e, ao mesmo tempo, utilizassem de diferentes tipos de figuras, tais como animações de computador e simulações, com o objetivo de criar habilidades para a compreensão do nível molecular.

Nesse sentido, podemos citar alguns trabalhos que corroboram com as ideias de Johnstone (1982/1993), como Gabel (1993), o qual destacou que o ensino de química deve ser pautado nos níveis submicroscópico (átomos/moléculas/íons), macroscópico (observáveis e tangíveis) e simbólico (fórmulas, estruturas, equações), e não apenas no nível simbólico, estava acontecendo. As pesquisas coordenadas por Treagust (CHITLEBOROUGH; TREAGUST, 2007; TREAGUST; CHITTLEBOROUGH; MAMIALA, 2003), por sua vez, têm publicado trabalhos referentes à habilidade de modelização e sua relação com o nível de representação submicroscópico proposto por Johnstone.

Nessa mesma perspectiva, Melo (2015) e Melo, M. e Silva, R. (2019) afirmam que a transição entre os níveis macroscópico, submicro e representacional pode ser facilitada pelo uso de estratégias, como os sistemas conceituais hierarquicamente organizados. Assim como, também, a transição entre os níveis submicroscópico e representacional pode ser facilitada pela utilização de modelos e modelagens.

A partir de 2009, começaram a surgir alguns estudos epistemológicos mais profundos na literatura questionando o tripleto, como é o caso do trabalho de Labarca (2010), o qual afirma haver equívocos filosóficos associados à confusão entre os planos de argumentação, ou os três níveis de representação, como proposto por Johnstone $(1982,1993,2000)$. O trabalho de Araújo Neto (2009) ressalta a importância da representação para o conhecimento químico, mas adverte o equívoco de se incluir as 
representações no mesmo horizonte ontológico dos níveis submicroscópicos e macroscópicos.

Um dos equívocos apontados nos trabalhos, os quais buscaram realizar um estudo epistemológico sobre o triângulo de Johnstone, está no fato de que o autor comete um equívoco do plano ontológico (correspondente ao nível macro e submicroscópico da matéria) com os planos linguístico/conceitual/representacional e matemático. De acordo com Labarca (2010), planos diferentes não poderiam estar representados como vértices em um mesmo triângulo, ou seja, como planos equivalentes. Podemos tomar o nível macroscópico e o nível submicroscópico como sendo níveis diferentes para um mesmo plano ontológico, pois fazem parte de uma mesma materialidade, de uma mesma razão de ser.

Se for equivocado apresentar o nível representacional no mesmo plano que os demais níveis compondo um triângulo, por que Johnstone o fez? De acordo com Melo, V. e Silva, J. (2020),

Johnstone (2009) explicou que o formato triangular que utilizou na apresentação das componentes do pensamento químico teve origem nos diagramas triangulares que expressam a composição de minerais de três componentes: dióxido de silício, óxido de magnésio e óxido de cálcio (MELO, V.; SILVA, J., 2020, p. 4).

Tendo em vista as diferentes críticas e as diferentes proposições alternativas ao triângulo de Johnstone, o presente trabalho soma-se a esse campo e tem como objetivo trazer, a partir do materialismo históricodialético, uma análise do movimento macroscópico e submicroscópico da matéria e, fundamentado nisso, discutir qual o papel da representação nesta análise. Isso é justificado por não observamos no levantamento teórico críticas que tomassem como embasamento os aspectos teóricometodológicos do marxismo para compreender aspectos da realidade estudados pela química para além da proposta de Johnstone.

Além disso, para não centrarmos apenas na crítica, apontaremos aspectos didático-pedagógicos que possam dar materialidade à discussão no campo do ensino de química para que a nossa concepção seja colocada em movimento na práxis educativa. Nesse sentido, buscamos 
incorporar as ideias de Johnstone e dos autores críticos a elas para apontar na direção da superação, a partir de um novo olhar teórico-filosófico. Desse modo, é necessário compreender alguns conceitos pertinentes que embasam esse estudo.

\title{
FUNDAMENTOS TEÓRICOS
}

Para embasar a nossa discussão tomaremos como pressuposto teóricofilosófico o materialismo histórico-dialético e a psicologia histórico-cultural.

Na perspectiva do materialismo histórico-dialético, defende-se como premissa do método de pesquisa a necessidade de compreender o objeto ou fenômeno na sua prática real. Os objetos e fenômenos da realidade existem de forma objetiva, ou seja, possuem existência independentemente do conhecimento e da consciência dos seres humanos. Cabe a nós, através da investigação, a compreensão das leis existentes que regem o mundo material, como nos dizem Martins e Lavoura (2018):

\begin{abstract}
Independentemente do conhecimento e da consciência humana sobre tal, os elementos constitutivos da prática social existem, são reais e possuem uma estrutura e dinâmica interna de funcionamento efetivo a qual pode ser apreendida pela consciência humana por meio, especialmente, da atividade de investigação científica. Decorre daí a necessidade da ciência na prática humana (MARTINS; LAVOURA, 2018, p. 225).
\end{abstract}

Em vista disso, homens e mulheres apreendem a realidade através de um método de investigação que possibilite chegar à compreensão e explicação da essência dos objetos e fenômenos, o que Ihes auxilia no agir no mundo. Nesta perspectiva, entendemos que "a realidade é cognoscível e que conhecemos efetivamente o objeto, não pela sua empiria imediata, mas pela mediação teórica que fazemos dessa empiria" (MESSEDER NETO, 2015, p. 155). É por meio da análise do objeto em sua materialidade, procurando suas determinações e sua essência, através da abstração, até atingir uma síntese teoricamente embasada, que conhecemos as coisas em seu movimento.

Conhecer um determinado objeto ou fenômeno, para o materialismo histórico-dialético, é reproduzir no plano do pensamento o movimento real 
deles. Entendemos aqui a reprodução não como uma imagem fotográfica, espelhamento imediato ou transposição mecânica, mas sim como uma reconstrução, no pensamento, daquilo que se passa na realidade, como processualidade histórica e dinâmica, características que são essenciais da realidade.

Dentro do processo de conhecer, a abstração é uma função do pensamento que permite isolar e examinar um determinado elemento extraído do fenômeno ou objeto de estudo, isto é, para compreender as variadas determinações que ele está sujeito, por meio da saturação da análise. Nesse sentido, apreender um fenômeno/objeto como uma síntese de múltiplas determinações significa apreendê-lo na sua complexidade, nos seus variados condicionantes, nas suas variadas relações que comportam sua existência objetiva. Investigar um objeto olhando para suas múltiplas determinações é buscar a lógica de sua existência, pois elas carregam os traços essenciais da sua dinâmica e estrutura fundante e de funcionamento.

No que se refere ao processo de abstração, em seus escritos Marx (2011) afirma que o verdadeiro conhecimento científico é o que se dá por meio da ascensão do abstrato ao concreto. Isso significa que o conhecimento concreto real é aquele que capta o conjunto de nexos e relações entre os elementos distintos que constituem a totalidade do objeto/fenômeno. Esse processo possibilita compreender aquilo que está sendo investigado, num movimento próprio da dialética - que vai do todo às partes e das partes ao todo, constantemente. Nesse sentido, de acordo com Lukács (2013), conhecer a totalidade não é conhecer tudo do objeto em estudo, mas apreender a sua lógica interna e que determina essa totalidade a partir das variadas determinações.

Ainda assim, é importante evidenciar que o objeto/fenômeno investigado é portador de variadas determinações, mas é o pensamento que as reproduz idealmente. Deste modo, quanto mais se satura um objeto de determinações, mais ele se concretiza. Para o sujeito, o objeto conhecido na sua dinamicidade e processualidade, saturado de determinações, tornase cada vez mais concreto, um concreto pensado (KOSIK, 2002). 
É importante compreender isso, pois há concepções de que a química é essencialmente uma ciência abstrata, devido aos entes submicroscópicos não tangíveis. A nossa defesa é de que a química, como qualquer outra ciência, parte da materialidade (seja no nível macroscópico ou submicroscópico) e utiliza do pensamento para abstrair aspectos necessários à compreensão dos fenômenos. Mas a verdadeira ascensão ao conhecimento químico ocorre quando as abstrações que foram analisadas pelo pensamento retornam à realidade, de modo a enxergá-la multideterminada e concreta. Portanto, do ponto de vista do pensamento, a química, assim como as outras ciências, é constituída de abstrações humanas. No entanto, do ponto de vista da realidade global, os fenômenos químicos existem na sua concreticidade. Isso também inclui os entes submicroscópicos da realidade.

Outro ponto válido de destaque é que o método do materialismo histórico-dialético supera as dicotomias próprias da lógica formal, a qual aponta que dentro de um mesmo sistema dedutivo não há a possibilidade de coexistir opostos, sendo ambos verdadeiros ou ambos falsos e, deste modo, um dos polos da oposição acaba por ser excluído (KOPNIN, 1978). A lógica dialética supera os enfoques dicotomizantes entre quantitativoqualitativo, subjetivo-objetivo, individual-social, indução-dedução, biológicocultural, macroscópico-submicroscópico etc., pois nela há a ideia de possibilidade de elaboração do conhecimento racional e objetivo da realidade humana na sua complexidade e totalidade, considerando as suas contradições como constituintes do objeto/fenômeno.

Entender o princípio da oposição e contradição, ou a negação da negação, é, para a lógica dialética, de suma importância, pois, para ela, a realidade apresenta uma unidade indissolúvel entre opostos (a unidade de contrários), o que determina saber o objetivo como subjetivo, o externo como interno, o qualitativo como quantitativo, o individual como social, e, para o nosso trabalho, o macroscópico como submicroscópico e vice-versa.

Opostos dialéticos são caracterizados pela sua interpenetração e também por duas especificidades: eles estão, reciprocamente, 
condicionando e, reciprocamente, excluindo. A primeira especificidade significa que a existência do polo de um par de opostos está condicionada pela existência do outro polo do par. Por exemplo, na química, o conceito de entes macroscópicos surge apenas porque ele produz o conceito oposto de entes microscópicos (ou melhor, submicroscópicos). Não faria sentido falar em algo macroscópico se não existisse o seu contrário. Dois tipos diferentes de níveis da realidade foram necessários para justificar os fenômenos químicos. Dessa maneira, a fonte dos conceitos de condicionamento recíproco entre $\bigcirc$ nível macroscópico e $\bigcirc$ nível submicroscópico é a existência objetiva de dois tipos de níveis do conhecimento químico tendo a sua relação dialética objetiva caracterizada pelo conceito. Isso provoca a impossibilidade de separação, a qual chamamos de "unidade de contrários".

Passando a discussão para o aporte teórico histórico-cultural, é preciso entender como compreendemos 0 processo de representação e simbolização para, assim, poder fundamentar a nossa crítica ao proposto por Johnstone.

A função da representação, para a química, de acordo com Araújo Neto (2009), transcende a mera função da comunicação entre os pares e envolve também a função heurística preditiva e explicativa. Ainda assim, as teorias em química, de maneira geral, materializam-se em representações, especialmente quando pensamos nas entidades corpusculares não observáveis (GRESCZYSCZYN, 2017). Além disso, podemos apontar que as elaborações simbólicas da química, de acordo com Vigotski (2009), promovem um desenvolvimento psíquico do ponto de vista das abstrações e generalizações, algo que não seria possível sem elas. E, ao mesmo tempo, abre a possibilidade de apontar para novas formulações, devido ao seu caráter sintético e sistemático.

Tal concepção corrobora a abstração como uma ferramenta teórica, a qual atua como mediadora da análise essencial da realidade objetiva e supera conclusões sustentadas nas definições imediatas da superficialidade 
aparente (VYGOTSKI, 1997). Ou seja, a relação da representação é, em última análise, um processo mediado.

Por etimologia, o termo "representação" provém da forma latina representare que significa fazer-se presente ou apresentar-se, manifestar-se de novo, fazer alguém ou alguma coisa presente, inclusive uma ideia, por intermédio de alguém ou objeto (PITKIN, 1972).

Defendemos, então, que a representação é caracterizada por processos de mediação em atividades simbólicas, assumindo que prevalece seu entendimento como um processo de substituição. Deste modo, o substituto, ou representante, está envolvido em uma estratégia complexa na qual toma o lugar de algo para alguém (ou para outro algo), ao mesmo tempo em que não é o representado, pois uma representação nunca é e nunca será uma cópia da realidade.

De acordo com Vigotski (2009), a representação se configura como signo; possível de comunicação, de imagem mental, de mediador da compreensão, de transformação intelectual. É preciso evidenciar que essas representações não têm o papel de estabelecer meramente uma "ponte", um "elo" ou um "meio" entre. Tomando como exemplo o campo da química, e o que tange à realidade submicroscópica e a macroscópica dos fenômenos químicos designados através das representações das estruturas dos átomos, moléculas, íons, fórmulas químicas, equações químicas, entre outros. Ao contrário disso, a mediação que esses símbolos desempenham é uma interposição que provoca transformação no sujeito, carregam a possibilidade de acesso às propriedades da realidade macro e submicroscópica, guardam a intencionalidade socialmente construída e promovem desenvolvimento psíquico.

Vigotski (2007) exemplifica sobre o processo do início da simbolização na criança no seguinte trecho:

[...] um pedaço de madeira torna-se um boneco e um cabo de vassoura torna-se um cavalo. A ação regida por regras começa a ser determinada pelas ideias e não pelos objetos. Isso representa uma tamanha inversão da relação da criança com a situação concreta, real e imediata, que é difícil subestimar seu pleno significado. A criança não realiza esta transformação de uma só vez por que é 
extremamente difícil para ela separar o pensamento (o significado de uma palavra) dos objetos (VIGOTSKI, 2007, p. 115).

Os processos de simbolização, geralmente, começam relacionando dois objetos, como exemplificado por Vigotski (2007) anteriormente, e vai se tornando algo cada vez mais complexo. Nesse sentido, é importante salientar sobre a não semelhança como cópia do desenho e da palavra com o objeto referendado, ocorrendo, assim, o processo de simbolização desencadeado por sua representação arbitrária. Vale ressaltar que tanto os instrumentos quanto os signos (símbolos) se incluem no conceito mais geral de atividade mediadora, isto é, "um tipo de atividade que permite aos que participem dela exercerem entre si, a partir de suas propriedades essenciais, uma influência recíproca" (MARTINS, 2015, p. 47). Entretanto, a mesma autora chama a atenção para o fato de que o conceito de mediação ultrapassa a ideia de uma mera relação aparente entre coisas, mas está dentro da esfera das intervinculações entre as propriedades essenciais das coisas, ou seja, algo que se interpõe e ao mesmo tempo carrega as propriedades tanto de um quanto de outro.

No que confere à discussão deste trabalho, conceber o signo dentro desta perspectiva psicológica é essencial, pois a química carrega formas de representações simbólicas que funcionam como signos, como mediadoras da compreensão desta Ciência.

\section{PARA ALÉM DO TRIÂNGULO DE JOHNSTONE}

É praticamente consenso na comunidade científica que os objetos, fenômenos e entes no nível macroscópico possuem existência material, mas isso não ocorre frequentemente com o nível submicroscópico, pois atribui-se aos entes submicro da realidade apenas uma existência ideal. Essa diferença, muitas vezes, se dá pelo fato de que não acessamos de forma direta os entes no nível submicroscópico através de sensibilidade física, seja humana ou de equipamentos. Porém, podemos acessá-los de forma indireta, a partir de tecnologias e de conhecimentos elaborados. Deste modo, há concepções mais idealistas que consideram entes químicos 
(átomos, moléculas e íons, por exemplo) como uma invenção puramente humana para explicar a realidade, sem uma relação próxima com a materialidade e existência factual desses entes.

A nossa concepção, baseada no referencial do materialismo históricodialético, defende, por meio do conhecimento histórico acumulado, que entes químicos submicroscópicos existem sim na sua materialidade e independente dos seres humanos. O fato de homens e mulheres em tempos mais anteriores não terem tecnologia e elaboração de conhecimento suficiente para acessar o nível submicro, e inferir sobre sua existência, não quer dizer que eles não existiam. Assim como não queremos dizer que as representações que fazemos atualmente desses entes dão conta da completude de determinações do objeto submicroscópico representado. Wartha e Rezende (2015) argumentam que esse cuidado filosófico do professor poderá contribuir para a superação de algumas dificuldades metodológicas e epistemológicas relacionadas aos entes químicos (itens ontológicos), não apenas no que se refere à sua existência, mas, também, às suas consequências de asserção. Ou seja, de que a realidade molecular é a causa dos fenômenos, e não explicação deles.

A nossa defesa é a de que o conjunto da materialidade submicro gera a materialidade macro. No entanto, isso não quer dizer que acreditamos que os modelos e representações dão conta da totalidade do nível submicro. Se não somos capazes de compreendê-los de forma direta e nem pelos sentidos, precisamos utilizar de mediações, das quais consistem as representações e modelos na sua dinamicidade. O fato, portanto, de apreender os entes submicro de forma mediada, a partir dos signos, a partir de elaborações conceituais, a partir de representações da realidade do que possam ser esses entes, não quer dizer que eles não possuam sua base de existência material e concreta.

Não podemos perder de vista que o representado é, normalmente, maior em funções e em atividades que seu representante. A representação simbólica, como sabemos, não tem e nunca terá como carregar todas as determinações, todas as características do ente representado. Todavia, 
nossa defesa sobre a natureza do processo representativo considera que essa incompletude não é prejuízo para a representação, mas o seu atributo mais vigoroso nas atividades da educação em química.

Vamos tomar um exemplo para tentar deixar mais claro o nosso argumento. Analisando características da substância propanona (acetona) em nível macroscópico, podemos citar: a) é uma substância que se apresenta no estado líquido à temperatura ambiente de $25^{\circ} \mathrm{C}$; b) é uma substância relativamente volátil, pois tem facilidade para evaporar; c) possui uma boa capacidade de se misturar com substâncias lipofilicas; entre outras. Para determinar essas características sobre a propanona não foi necessário saber sua composição química, sua fórmula química e nem a estrutura da molécula. Mas, para que se possa explicar quimicamente, nos modos científicos vigentes, cada uma dessas características, faz-se necessário acessar o nível submicroscópico. E, nesse caso, a representação estrutural da molécula se faz imprescindível, visto que apenas a representação da substância através da sua fórmula química não dá conta de justificar suas propriedades devido à existência de isômeros.

As diferentes formas de representação, como a fórmula química, a estrutura molecular, a nomenclatura, os gráficos de absorção de infravermelho etc., devem atuar como formas que generalizam cada vez mais a compreensão do ente químico submicroscópico e dos fenômenos perceptíveis macroscopicamente. Mas é preciso lembrar que essas representações têm o papel mediador entre os dois níveis da realidade.

Os cientistas fizeram uso de conhecimentos e técnicas que thes possibilitaram inferir sobre a existência desses entes e de como se comportam, gerando representações deles. É a partir destas representações que podemos acessar o nível submicroscópico e justificar as propriedades e os fenômenos que observamos em nível macroscópico. Com isso, defendemos neste trabalho o caráter mediador das representações entre as esferas do mundo macroscópico com o mundo submicroscópico.

O conhecimento proporcionado pelo estudo da representação dos entes químicos submicroscópicos é considerado verdadeiro quando 
confrontado com o que se conhece dessas substâncias por meio de suas manifestações empíricas. Todavia, o desenho de uma estrutura molecular, por exemplo, é uma aproximação incompleta, seja em representações bidimensionais (em papel) ou tridimensionais (em softwares modernos). Essa é uma característica ontológica que distingue o ente químico de sua representação, e coloca a comunidade de químicos e seus aprendizes diante da necessidade de uma consciência cuidadosa entre a representação e a coisa a ser representada (ARAÚJO NETO, 2012).

A forma de ver a realidade química, a partir do que foi explanado, nos coloca, portanto, em contradição dialética, lidando com dois opostos interpenetrantes: os níveis macroscópicos e submicroscópicos possuem uma relação de dependência, na qual um condiciona a existência do outro. A química se caracteriza por explicar seus fenômenos baseando-se na existência de partículas, sendo que as alterações no arranjo ou interações entre essas partículas causam mudanças que podem ser observadas macroscopicamente (CEDRAN, D.; CEDRAN, J.; KIOURANIS, 2018).

A simbologia manifestada na representação de estruturas moleculares, por exemplo, se configura como mediadora das duas esferas (macroscópica e submicroscópica), pois permite aos que participam da relação, a partir de suas propriedades essenciais, exercerem entre si uma influência recíproca. Desse modo, não faz sentido, então, dizer que a aprendizagem da Química está condicionada ao trânsito entre os "três níveis" do conhecimento, mas sim da unidade entre os dois níveis. Contudo, se ficarmos apenas no nível macro, no fenômeno aparente, não há aprendizagem científica/química, e, para conhecer a esfera submicroscópica, faz-se necessária a mediação simbólica.

A figura 2 abaixo sintetiza a nossa concepção. 
FIGURA 2 - Relação entre as esferas macroscópicas e submicroscópicas da realidade e do conhecimento químico

Macro $\leftrightharpoons$ Símbolo/ Signo/ Representação $\Longleftrightarrow$ Submicro

Fonte: elaborada pelo autor.

Deixamos claro que a nossa concepção é completamente diferente da proposta por Johnstone (1982, 1993), o qual considera símbolo/representação como dimensão/nível do conhecimento químico. Nossa defesa é a de que, apesar da representação se relacionar com as outras dimensões/níveis, ela está à parte deles, em outro plano. Argumentamos em defesa de que o símbolo/representação/signo é o mediador e se interpõe às esferas macro e submicroscópicas.

Outro ponto que merece destaque é o de não estarmos propondo um simples redimensionamento do triângulo de Johnstone. A nossa proposição vai à direção de uma mudança na compreensão da realidade, a partir de uma base filosófica que considera o mundo na sua materialidade multideterminada e contraditória, exibindo a representação como a forma pela qual o sujeito acessa e entende esse mundo, ao mesmo tempo em que se transforma nessa apreensão.

Nesse sentido, é importante deixar claro que a representação não existe sozinha; representar é representar algo. Para a psicologia históricocultural, se um ensino for focado na representação na sua relação com aquilo que representa, será um ensino concreto. Assim, se a atividade pedagógica foca em escrever equações, símbolos, ou fórmulas por si só, ela não é um ensino do representacional. Os modelos, as fórmulas químicas, nomenclaturas, entre outras representações, só apresentam o seu verdadeiro significado e só adquirem concretude na sua relação de unidade com aquilo representado, com os níveis macroscópicos e submicroscópicos da realidade. Em síntese, diferente do que comumente é propagado, queremos um ensino focado no representacional. Queremos um 
ensino que os signos químicos representem, de fato, o mundo material no seu movimento macroscópico-submicroscópico. A representação, para a psicologia histórico-cultural, não se aparta do mundo material, ao contrário, ganha status de signo quando amplia o acesso do sujeito ao mundo concreto e dá possibilidades para ele transformá-lo. Não seria esse o objetivo do ensino da química?

Passaremos a discutir alguns aspectos didáticos do ensino de química, a partir das nossas concepções que foram explanadas, de modo a deixar os fundamentos que aqui anunciamos mais claros.

\section{O ENSINO DE QUÍMICA COMO UNIDADE DIALÉTICA ENTRE O MACRO E O SUBMICROSCÓPICO}

Antes de tudo, deixaremos evidente que, de acordo com Martins (2013), todo e qualquer ensino deve ser pensado em três aspectos que se relacionam: conteúdo, forma e destinatário. É preciso que o professor tenha pleno domínio do conteúdo que vai ensinar, nas variadas determinações e saiba identificar aquilo que é essencial para o processo de humanização do aluno. Além disso, conhecer o destinatário para quem serve o seu ensino também cabe ao professor. É evidente que o conteúdo do ensino não será igual para alunos de diferentes regiões, faixas etárias, classe social, entre outras determinações que objetivam o sujeito. Junto a isso, a melhor forma com a qual o professor irá ensinar determinado conteúdo para determinado aluno depende destes e da realidade objetiva na qual estão inseridos. Por isso, não existem melhores formas e técnicas de ensino em si, pois elas dependem do que iremos ensinar e para quem iremos ensinar.

Em vista disso, daremos um exemplo hipotético de ensino para que a nossa proposição sobre a relação de unidade dialética entre os níveis macroscópicos e submicroscópicos mediados pela representação ganhe materialidade. Não temos intenção aqui de dar receitas dizendo que "esta é a forma de ensinar", mas desejamos mostrar como tais aspectos podem ganhar concretude sem, no entanto, dizer quantas aulas o professor deverá usar, ou mesmo para qual série específica dos anos finais da educação 
básica. Cabe ainda destacar que não trazemos nenhuma novidade em termos de procedimentos didáticos, mas queremos mostrar que fundamentos teórico-metodológicos diferentes apontam para outra forma de trato com o conhecimento.

Em uma aula de química para o Ensino Médio, o professor pretende ensinar sobre a representação estrutural da substância etanol. Para isso, ele pode começar apontando ou questionando sobre os aspectos dessa substância que são perceptíveis para o estudante, primordialmente, em seus traços mais imediatos. Por exemplo: qual o estado físico do etanol? Qual a coloração dessa substância? Ao passar um algodão embebido de etanol na pele, qual a sensação que temos? (Pode-se realizar a experiência, caso possível). Comparado com a água, o etanol evapora com mais facilidade ou não? Onde o etanol, também muito conhecido popularmente como álcool, pode ser encontrado na prática social? Como o etanol é produzido até ser comercializado? Essas podem ser algumas das questões introdutórias levantadas pelo professor, podendo ser apresentadas através de perguntas direcionadas aos alunos ou não.

É necessário, nesse primeiro momento, que fique claro para 0 estudante que o etanol é uma substância líquida na temperatura ambiente, que possui a característica de ser relativamente volátil, que tem a capacidade de se misturar com substância hidrofílicas e lipofílicas etc. Além disso, é importante destacar que essa substância é utilizada e produzida dentro de relações sociais multideterminadas.

O etanol, por exemplo, é utilizado na produção de bebidas, cosméticos, aromatizantes, solventes, produtos de limpeza, remédios, combustível de veículos, entre outros. E essa diversidade na utilização do etanol só pode existir devido a um sistema de produção. Sistema esse que não se preocupa com o meio ambiente, com a saúde do trabalhador e que promove o aumento da desigualdade social. No Brasil, a matéria-prima majoritária que produz o etanol é a cana de açúcar, e o seu plantio em grande escala provoca, entre outras coisas, a existência de monoculturas em determinadas regiões, o desmatamento, a concentração de terra em 
grandes latifúndios, a perda da biodiversidade, a concentração de renda na mão dos donos dos latifúndios e a condição de trabalho é, muitas vezes, análoga à escravidão.

É importante que o estudante se aproprie, então, não só do que tange às características da substância em si, mas das suas determinações diversas dentro de relações sociais concretas.

O professor conduz o estudante sobre a necessidade de explicar as características do etanol observadas. Necessidades que surgiram, historicamente, quando o ser humano se propôs em explicar a natureza ao seu redor. Por exemplo: por que o etanol é mais volátil do que a água? Ou então, por que o etanol possui uma melhor solubilidade com a gasolina, se comparado com a água? Por que o etanol e o metoximetano, substâncias com a mesma fórmula química (isômeros), possuem propriedades físicoquímicas distintas? Essas questões moveram os cientistas a buscar, na constituição das substâncias, as respostas. Nesse sentido, foram elaboradas formas para acessar o mundo submicroscópico (não visível), intangível aos seres humanos de forma direta. Assim, foi através de representações das estruturas que pudemos compreender como a natureza funciona para além do que vemos e/ou sentimos.

Essas representações, como a do etanol (Figura 3), possibilitaram a construção de teorias capazes de explicar os fenômenos que observamos no nível macroscópico, como as diferentes forças de interação entre as moléculas para explicar volatilidade e solubilidade. Essas representações estruturais dos compostos da química orgânica funcionam como aquilo que une os níveis macroscópicos e submicroscópicos da matéria, pois carregam o essencial para explicar os fenômenos químicos.

Figura 3 - Representação estrutural do etanol

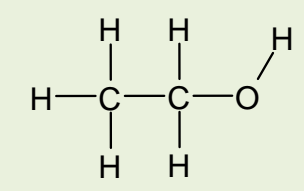

Fonte: Elaborada pelo autor. 
Ao trabalhar com a estrutura do etanol, o professor convocará o aluno a refletir que a mesma estrutura pode ajudar a pensar o nível macroscópico que tem a representação física e o submicroscópico. Veja que aqui a possibilidade de instaurar a contradição de uma mesma representação pode ajudar a acessar o empírico, ir além dele e explicá-lo. Ensinar a representação do etanol não é apenas ensinar a contar carbonos ou fazer traços da ligação. A representação é ensinada como a forma que desenvolvemos para falar da realidade e que não tem sentido falar dela sem que possamos construir imagens da camada macro ou submicro da realidade. Não existe o momento de ensinar a representação, mas será sempre relacionada ao que ela significa no macro ou no submicroscópico. É importante destacar para o aluno que: 1) as moléculas representadas por essas estruturas não estão sozinhas, mas em um aglomerado de várias delas e interagindo entre si para que possam gerar as propriedades das substâncias; 2) a representação estrutural do etanol e de outras substâncias não é uma cópia de como realmente a molécula é, são formas de simbolizar para que possamos melhor estudá-las e compreender a realidade. Por isso, as representações podem ser de diferentes formas.

As considerações feitas sobre o etanol foram realizadas para deixar evidente, principalmente ao leitor, a relação da unidade entre os níveis macroscópicos e submicroscópicos e as várias determinações que essa substância possui dentro de relações sociais concretas.

É importante destacar que os conceitos ensinados não se esgotam a partir da primeira apropriação do aluno com este. Pois, como Vigotski (2009) nos ensina: quando um conceito é apropriado, o seu caráter de generalização está só começando. Nesse sentido, a organização do ensino precisa possuir um caráter de espiral ascendente, de modo que as representações estruturais estudadas ganhem cada vez mais determinações e enriqueçam de relações para que, assim, passemos do pensamento sincrético ao pensamento sintético no aluno.

Defendemos também que a proposição aqui trazida não precisa ser feita com cada substância trabalhada pelo professor, visto que isso não 
caberia no tempo escolar. Porém, para cada representação usada, o professor precisa garantir que o aluno está entendendo o referente macroscópico ou submicroscópico, caso contrário, corre o risco de estar realizando um ensino sem sentido que não promove desenvolvimento.

\section{CONSIDERAÇÕES FINAIS}

A importância da compreensão sobre o papel das representações para a Química fica evidente quando destacamos que, além de promover a mediação entre a realidade objetiva fenomênica e o intelecto do sujeito, passando pela abstração, ela também assume o papel de mediar as esferas da materialidade macroscópicas com as submicroscópicas. Deste modo, reforçamos que não há como entender a matéria, nos moldes atuais, sem a relação dos aspectos macro e submicro na química. Aspectos que são mediados pelas representações.

A relação entre essas dimensões pode ser observada, por exemplo, quando um químico trabalhando no laboratório elabora a síntese de um composto e, para verificá-lo, utiliza de indícios de absorção de infravermelho, absorção atômica e entre outros métodos de caracterização para estabelecer a relação com sua estrutura submicroscópica. Ou seja, utilizam-se de técnicas experimentais embasadas de teorias, modelos, símbolos representacionais e de signos para promover a mediação entre a esfera fenomênica da aparência macroscópica com a esfera submicroscópica. A partir da síntese dessa unidade (macro-submicro), levando em consideração a sua dinâmica, chega-se à essência.

Imagine que há, até então, uma fronteira entre os níveis macroscópicos e submicroscópicos da realidade. A aparência que se mostra na sua imediaticidade ou que possui mediações mais simples (dados empíricos da realidade, por exemplo) está do lado macroscópico da fronteira. No entanto, quando utilizamos da ciência, a partir de um aparato lógico-metodológico dialético, investigando o objeto/fenômeno mais a fundo, buscamos romper essa fronteira, de modo a estabelecer uma relação de unidade entre esses dois níveis. O rompimento dessa fronteira só é possível 
a partir de um pensamento teórico conceitual, de mediações simbólicas que nos conduz à essência. Nesse sentido, como unidade, a aparência fenomênica carrega elementos da essência, mas não a revela de imediato. Assim como a essência contém aquilo que nos é dado na aparência. Por isso, se a aparência das coisas coincidisse com a sua essência, toda a ciência seria sem valia (MARX, 2017). Deste modo, para a consciência filosófica dialética, só o pensamento conceitual e somente o mundo conceituado é, efetivamente, a realidade. Por fim, é a unidade entre os níveis macroscópicos e submicroscópicos, mediada pela representação estrutural, que confere a verdadeira concreticidade ao objeto/fenômeno.

A nossa concepção, então, vai de encontro à ideia do triângulo de Johnstone e propõe uma nova formulação para a compreensão dos fenômenos químicos. Portanto, somos cientes da importância que as ideias do autor tiveram para o debate no ensino de química, mas que elas foram situadas no seu tempo. Assim, apontamos para uma nova concepção que incorpora o que está posto e aponta para sua superação, a partir de uma análise materialista dialética.

Em termos da prática pedagógica, o professor precisa estar consciente de que essas representações dotadas de significados desempenham uma interposição que promove a compreensão na sua essência. Por carregar as propriedades do nível macro e submicroscópico da realidade, guarda a intencionalidade socialmente construída e possibilita transformação e desenvolvimento psíquico do estudante.

Desse modo, as aulas deveriam ter como horizonte instalar a contradição entre a aparência e a essência, e isso só se dá na relação empiria-teoria, mediada pela representação. Qualquer um desses polos não alcança as potencialidades de um ensino pautado na lógica dialética.

\section{REFERÊNCIAS}

ARAÚJO NETO, W. N. Formas de uso da noção de representação estrutural no Ensino Superior de Química. 2009. 228 f. Tese (Doutorado) - Programa de PósGraduação em Educação, Faculdade de Educação, Universidade de São Paulo, São Paulo, 2009. 
ARAÚJO NETO, W. N. Estudos sobre a Noção de Representação Estrutural na Educação em Química a Partir da Semiótica e da Filosofia da Química.

Revista Virtual de Química, v. 4, n. 6, p. 719-738, nov. 2012.

CEDRAN, D. P.; KIOURANIS, N. M. M. CEDRAN, J. C. A importância da simbologia no ensino de Química e suas correlações com os aspectos macroscópicos e moleculares. Rencima,[S.L], v. 9, n. 4, p. 38-57, out. 2018.

CHITTLEBOROUGH, G.; TREAGUST, D. F. The modelling ability of non-major chemistry students and their understanding of the sub-microscopic level.

Chemistry Education Research and Practice, Cambridge, UK, v. 8, n. 3, p. 274292, 2007.

GABEL, D. Use of the particulate nature of matter in developing conceptual understanding. Journal of Chemical Education, v. 70, n. 3, p. 193-194, 1993.

GILBERT, J.; TREAGUST, D. Introduction: macro, submicro and symbolic representations and the relationship between them: key models in chemical education. In: GILBERT, J. e TREAGUST, D. (Ed.). Multiple Representations in Chemical Education: Springer Netherlands, v.4, 2009. cap. 1, p. 1-8. (Models and Modeling in Science Education).

GRESCZYSCZYN, M. C. C. Múltiplas representaçōes para o ensino de química orgânica: uso do infográfico como meio de busca de aplicativos. 2017.99 f. Dissertação (Mestrado) - Programa de Pós-Graduação em Ensino de Ciências Humanas, Sociais e da Natureza, Universidade Tecnológica Federal do Paraná, Londrina, 2017.

JOHNSTONE, A. H. Macro- and microchemistry. School Science Review, v. 64, p. 377-379, 1982.

JOHNSTONE, A. H. The Development of Chemistry Teaching. The Forum, v. 70, n. 9, p. 701-705, 1993.

JOHNSTONE, A. H. Teaching of chemistry: logical or psychological? Chemistry Education: research and practice in Europe, v. 1, n. 1, 2000.

JOHNSTONE, A. H. The future shape of chemistry education. Chemistry Education: research and practice, v. 5, n. 3, 2004.

KOPNIN, P. V. A dialética como lógica e teoria do conhecimento. Rio de Janeiro: Civilização Brasileira, 1978.

KOSIK, K. Dialética do concreto. 7. ed. Rio de Janeiro: Paz e Terra, 2002. 
LABARCA, M. Acerca del triangulo de Johnstone: algunos comentarios filosóficos. In: CONFERÊNCIA LATINO-AMERICANA DO INTERNATIONAL HISTORY, PHILOSOPHY AND SCIENCE TEACHING GROUP, 1., 2010, Maresias. Caderno de resumos... São Paulo: USP, 2010. p. 101.

LUKÁCS, G. Para uma ontologia do ser social II. São Paulo: Boitempo, 2013.

MARTINS, L. M. O Desenvolvimento do Psiquismo e a Educação Escolar: contribuições à luz da psicologia histórico-cultural e da pedagogia históricocrítica. Campinas, SP: Autores Associados, 2013.

MARTINS, L. M. A internalização de signos como intermediação entre a psicologia histórico-cultural e a pedagogia histórico-crítica. Germinal: Marxismo e Educação em Debate, Salvador, v. 7, n. 1, p. 44-57, jun. 2015.

MARTINS, L. M.; LAVOURA, T. N. Materialismo histórico-dialético: contributos para a investigação em educação. Educar em Revista, [S.L.], v. 34, n. 71, p. 223-239, out. 2018.

MARX, K. Grundrisse: manuscritos econômicos de 1857-1858: esboço da crítica da economia política. São Paulo: Boitempo, 2011.

MARX, K. O capital: crítica da economia política. São Paulo: Boitempo, 2017. (Livro 3: o processo global da produção capitalista).

MELO, M. S. A transição entre os níveis - macroscópico, submicroscópico e representacional - uma proposta metodológica, 2015, 134f. Dissertação (Mestrado) - Curso de Mestrado Profissional em Ensino de Ciências Universidade de Brasília, Brasília, 2015.

MELO, M. S.; SILVA, R. R. Os três níveis do conhecimento químico: dificuldade dos alunos na transição entre o macro, o submicro e o representacional.

Revista Exitus, Santarém/PA, v. 9, n. 5, p. 301-330, 11 dez. 2019.

MELO, V. F.; SILVA, J. L. P. B. Os níveis de pensamento químico de Johnstone, são níveis? In: ENCONTRO NACIONAL DE ENSINO DE QUÍMICA, 20., 2020, Recife. Anais [...] Recife: UFPE, 2020. p. 1-12.

MESSEDER NETO, H. S. Contribuições da psicologia histórico-cultural para ludicidade e experimentação no ensino de química: além do espetáculo, além da aparência. 2015. 253 f. Tese (Doutorado) - Curso de Programa de Pós-Graduação em Ensino, Filosofia e História das Ciências, Instituto de Física, Universidade Federal da Bahia/Universidade Estadual de Feira de Santana, Salvador, 2015. 
MORTIMER, E. F.; MACHADO, A. H.; ROMANELLI, L. I. A proposta curricular de química do Estado de Minas Gerais: fundamentos e pressupostos. Química Nova, v. 23, p. 273-283, 2000.

PITKIN, H. F. The concept of representation. Londres: University of California Press, 1972.

RAUPP, D.; SERRANO, A.; MOREIRA, A. M. A evolução histórica da linguagem representacional química: : uma interpretação baseada na teoria dos campos conceituais. In: ENCONTRO NACIONAL DE PESQUISA EM EDUCAÇÃO EM CIÊNCIAS, 7., 2009, Florianópolis. Anais [...]. Florianópolis: UfSC, 2009. p. 112.

TALANQUER, V. Macro, submicro, and symbolic: the many faces of the chemistry "triplet". International Journal of Science Education, v. 33, n. 2, p. 179-195, 2011.

TREAGUST, D. F.; CHITTLEBOROUGH, G.; MAMIALA, T. L. The role of submicroscopic and symbolic representations in chemical explanations. International Journal of Science Education, Abingdon, v. 25, n. 11, p. 13531368, 2003.

VIGOTSKI, L. S., A formação social da mente: o desenvolvimento dos processos psicológicos superiores. 7. ed. São Paulo: Martins Fontes, 2007.

VIGOTSKI, L. S. A construção do pensamento e da linguagem. Tradução de Paulo Bezerra. 2. ed. São Paulo: Martins Fontes, 2009.

VYGOTSKI, L. S. Obras escogidas I: el significado histórico de la crise de la psicología. Madrid: Visor, 1997.

WARTHA, E. J.; REZENDE, D. B. Os níveis de representação no ensino de química e as categorias da semiótica de Peirce. Investigações em Ensino de Ciências, [S.L.], v. 16, n. 2, p. 275-290, 2011.

WARTHA, E. J.; REZENDE, D. B. A elaboração conceitual em química orgânica na perspectiva da semiótica Peirceana. Ciência \& Educação (Bauru), [S.L.], v. 21, n. 1, p. 49-64, mar. 2015.

Recebido em: 21 de julho de 2021. Aprovado em: 04 de dezembro de 2021. Publicado em: 17 de dezembro de 2021.

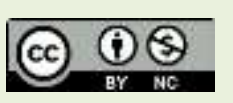

